\title{
OPASOK Z POHREBISKA V MORAVIČANOCH AKO DOKLAD NADREGIONÁLNYCH KONTAKTOV PLATĚNICKEJ KULTÚRY
}

\author{
Erika Makarová
}

DOI: https://doi.org/10.31577/szausav.2019.suppl.1.19

Keywords: Hallstatt period, Platěnice culture, contacts, belt hook, sheet-metal belt

\begin{abstract}
Belt from the cemetery in Moravičany as an evidence of the supra-regional contacts of the Platěnice culture
The paper presents original research of metal parts of belts from the cemetery of the Platěnice culture in Moravičany (Šumperk District). We have analysed the finds of iron rhombic belt hooks and decorated bronze sheet fragments, the latter being remnants of either sheet-bronze belt or rectangular sheet-bronze belt hook. Both kinds of finds represent exceptional part of costume of the Platěnice culture and are characteristic for the costume of the western Hallstatt and southeastern Hallstatt culture.
\end{abstract}

\section{ÚVOD}

Opasok predstavuje súčast’ odevu, ktorá mala (nielen) v praveku široké uplatnenie. Popri jeho vyslovene praktickej funkcii, ktorou bolo zopnutie odevu alebo pripevnenie rôznych predmetov dennej potreby, toaletných predmetov či zbraní, mohol mat̉ tiež nepochybne ozdobnú funkciu, ked' slúžil ako efektívny módny doplnok. Okrem toho mu možno priradit i symbolickú a sociálnu funkciu (Heynowski 2017, 11, 12; Kos 2004, 272-290; Rebay 2006a, 173). O využívaní opasku ako súčasti kroja v dobe halštatskej svedčia nielen nálezy kovových častí opaska, ale i vyobrazenia na situlovom umení (pozri Lenneis 1972; Lucke/Frey 1962).

V prostredí platěnickej kultúry na Morave sú opasky doložené skôr len výnimočne. Je to pravdepodobne spôsobené tým, že dominovali opasky zhotovené výlučne z organických materiálov, ktoré sa v našich geograficko-pedologických podmienkach nezachovali. O využívaní kovových súčastí svedčia predovšetkým zriedkavo sa objavujúce železné pásové zápony a pravdepodobne aj uzatvorené bronzové či železné krúžky, ktoré možno vo viacerých prípadoch považovat’ za opaskové krúžky. Popri takýchto bežne sa vyskytujúcich krúžkoch, ktoré sa na pohrebisku v Moravičanoch objavili vo viacerých hroboch (Makarová 2017a, 70, 71), sa v štyroch hroboch nachádzali súčasti opasku, ktoré priamo poukazujú na kontakty platěnickej kultúry s halštatskou kultúrou. Medzi nimi sa objavili aj fragmenty zdobeného bronzového plechu, ktoré dosvedčujú, že v kroji platěnickej kultúry mal svoje výnimočné postavenie aj bronzový plechový opasok, prípadne opasok, ktorého súčastou bola bronzová plechová zápona či kovanie.

\section{NÁLEZISKO}

Pohrebisko v Moravičanoch (okr. Šumperk) sa nachádzalo na severozápadnom okraji obce, v polohe nazývanej Dílečky. V rokoch 1953-1955 a 1958-1968 sa tu pod vedením J. Nekvasila z vtedajšieho Archeologického ústavu ČSAV v Brne uskutočnil rozsiahly systematický archeologický výskum (Nekvasil 1982). Počas neho sa na ploche približne $17200 \mathrm{~m}^{2}$ preskúmalo 1260 hrobov, ktoré spadali do obdobia trvania lužickej a platěnickej fázy kultúry lužických popolnicových polí. Pohrebisko je tak doposial' nielen najväšším pohrebiskom kultúry lužických popolnicových polí v Českej republike, ale počtom 330 hrobov zo staršej doby železnej, je aj najväčším pohrebiskom platěnickej kultúry. Pri riešení celkovej problematiky platěnickej kultúry tak predstavuje jedno z klúčových nálezísk (Makarová 2017a). 


\section{Opis nálezov}

\section{Železná pásová zápona (obr. 1: 1a)}

Opis nálezu: fragment železnej pásovej zápony rombického tvaru s odlomenými koncami, na zadnej strane pritavený amorfný železný predmet; rozmery: zach. dí. $8,4 \mathrm{~cm}, \breve{s} .4,6 \mathrm{~cm}, \mathrm{hr} .0,7 \mathrm{~cm}$.

Miesto nálezu: Moravičany, poloha Dílečky, komorový hrob 1000.

Sprievodné nálezy: 19 keramických nádob, železný nôž, dva železné hroty šípu, bronzový uzatvorený krúžok (obr. 1: 1b), bronzová ihlica a bronzový drôt.

\section{Bronzový plechový opasok/pásová zápona (obr. 3: 1)}

Opis nálezu: niekol'ko zlomkov bronzového plechu zdobeného vybíjanou výzdobou: vertikálna línia vedená pozdíž okraja a šikmé línie vychádzajúce z kruhu; dva zlomky majú železný nit; rozmery: hr. 0,6 cm.

Miesto nálezu: Moravičany, poloha Dílečky, urnový hrob 1119.

Sprievodné nálezy: dve keramické nádoby, železný nôž, železná ihlica, železná tyčinka (ihlica?), bronzová ihlica, železný krúžok (obr. 3: 2), dva bronzové špirálovité náramky a fragment železného predmetu (obr. 3: 3).

\section{Železná pásová zápona (obr. 1: 2)}

Opis nálezu: fragment železnej pásovej zápony rombického tvaru so zachovaným koncom ohnutým do háčika, druhý (záchytný) koniec odlomený; rozmery: zach. dí. 10,9 cm, š. 2,7 cm, hr. 0,6 cm.

Miesto nálezu: Moravičany, poloha Dílečky, komorový hrob 1144.

Sprievodné nálezy: 25 keramických nádob, železný nôž, železná britva?, železný predmet, železná ihlica, dva fajansové koráliky a dva sklené koráliky.

\section{Železná pásová zápona (obr. 1: 3)}

Opis nálezu: fragment železnej pásovej zápony rombického tvaru, jeden koniec odlomený, druhý koniec ukončený zaoblením s nitom v strede, ktorým je pripevnený zlomok železného pásu; rozmery: zach. dî. 10,8 cm, š. 3,5 cm, hr. 0,5 $\mathrm{cm}$.

Miesto nálezu: Moravičany, poloha Dílečky, komorový hrob 1145.

Sprievodné nálezy: 19 keramických nádob, železný nôž, železná pinzeta, bronzový náramok, štyri sklené koráliky.

\section{ANALÝZA NÁLEZOV}

\section{Pásové zápony rombického tvaru}

V rámci rozšírenia platěnickej kultúry na Morave predstavujú tri železné pásové zápony rombického tvaru z komorových hrobov (hrob 1000, 1144 a 1145) v Moravičanoch dosial najväčšiu koncentráciu týchto zápon, keď̌e je bezpečne doložených len pät exemplárov tohto tvaru (obr. 1;2).

Deliacim kritériom pri pásových záponách býva jednak tvar stredovej časti, jednak tvar záchytného konca. Žial', ani jeden kus sa nezachoval neporušený, takže nevieme presne určit, o ktorý variant sa jedná, t. j. aký bol tvar ukončenia. $V$ tomto prípade môže byt̉ deliacim kritériom jedine ich šírka, ktorá sa značne líši (najužší exemplár má šírku 2,7 cm, najširší 4,6 cm).

V hrobe 1000 sa okrem železnej pásovej zápony (obr. 1: 1a) nachádzal aj bronzový uzatvorený krúžok kosoštvorcového prierezu (obr. 1: 1b), ktorý s najväčšou pravdepodobnostou tvoril súčast' opaska. Výbornou analógiou je napríklad nález pásovej zápony prichytenej o krúžok, ktorý sa našiel na pohrebisku v Bischofshofen-Pestfriedhofe (Lippert/Stadler 2009a, 43; 2009b, tab. 166: 556/12). Zatial' čo pásová zápona z hrobu 1144 má zachovaný koniec ohnutý do háčika, ktorý slúžil na zapnutie opasku (obr. 1: 2), druhý koniec pásovej zápony, slúžiaci na pripevnenie k organickej časti opasku, je čiastočne známy v prípade exemplára z hrobu 1145 (obr. 1: 3). Táto pásová zápona je ukončená zaoblením, v jeho strede je nit, ktorým bol pripevnený pravdepodobne železný pás. Obdobné je to $\mathrm{v}$ prípade železných pásových zápon s prinitovaným kovaním, ktoré sa vyskytujú v pol’skom Sliezsku (Ibragimow 2011, 8, 9, obr. 3: 3, 4). Rovnaké ukončenie opatrené otvorom na nit má aj pásová zápona nájdená na pohrebisku v Hallstatte, ktorá je však zhotovená z bronzu (Kromer 1959b, tab. 43: 6). Záchytný koniec zvyšných dvoch exemplárov sa nedochoval, takže nevieme, či bol rovnaký ako predošlé, alebo iný, a to v tvare písmena $\mathrm{T}$ alebo rybieho chvosta. Používanie pásových zápon s oboma poslednými menovanými tvarmi záchytných koncov je v prostredí platěnickej kultúry doložené dvoma exemplármi, ktoré sa na rozdiel od tých moravičanských zachovali vcelku. Zápona s koncom v tvare písmena T pochádza z Uherského Ostrohu-Ostrožského Předměstí (obr. 1: 5). Podl’a správy učitela F. Myklíka (1887, 82, 83, obr. 6: 16), ktorý nález v 80. rokoch 19. stor. objavil, sa "dosti zachovalá" železná zápona nachádzala v popolnici, pričom išlo o jeden z troch hrobov ležiacich $\mathrm{v}$ jednej línii, od seba vzdialených $4 \mathrm{~m}$. O prípadných d’alších nálezoch 
v hrobe zmienka nie je. Záchytný koniec v tvare rybieho chvosta má posledný známy exemplár rombickej pásovej zápony (obr. 1: 4), pochádzajúci z bohatého hrobu v Dobrčiciach (okr. Přerov). V hrobe sa d’alej nachádzala železná kopija a udidlo, dva bronzové náramky, keramika a kostený picí roh, na ktorom je vyrytý dvojzáprah so štvorkolesovým vozom (Červinka 1938, 78-80, obr. 1). Voz ako symbol výnimočnosti sa objavoval v západohalštatskej kultúre, kde sa dostával do hrobov miestnych elít (Makarová 2017b; Pare 1987). Ojedinele sa však môžeme stretnút aj s jeho vyobrazením na predmetoch, pričom zo západohalštatskej kultúry sú známe len dve takéto vyobrazenia. Naopak, objavuje sa na územiach, kde sa hroby s vozmi neobjavujú. Vyobrazenie štvorkolesového voza je známe $\mathrm{z}$ dvoch nádob zo Soprone či z viacerých tvárových urien v Pomoransku (Pare 1987, 212-219, obr. 14, 16-19). Hrob v Dobrčiciach teda môžeme na základe nálezov priradit k výnimočným hrobom platěnickej kultúry a právom sa môžeme domnievat', že v ňom bol pochovaný muž s vyšším sociálnym statusom (Makarová 2013, 102, 103).

Fragment železnej pásovej zápony (obr. 1: 6) sa našiel aj v hrobe 4 na pohrebisku v Mohelnici (okr. Šumperk; Stuchlík 2004, 523, obr. 3: 4). V tomto prípade sa však dochovala len čast’ s háčikom, takže nie je možné určit, aký tvar malo telo zápony. Popri rombických záponách sa totiž objavujú aj zápony oválneho tvaru (Gedl 1991, 82, obr. 42: 4; Kossack 1959b, tab. 98: 8; Stegmann-Rajtár 1992, 45, tab. 88: 4) či tvaru rovnoramenného trojuholníka so zaoblenými okrajmi pri základni (Ibragimow 2011, 7, obr. 2), ktoré síce doposial' nie sú doložené v prostredí platěnickej kultúry, ale objavujú sa v susedných kultúrach.

V prostredí platěnickej kultúry vo východných Čechách sa so železnými pásovými záponami stretávame len výnimočne (napr. pohrebisko v Platěniciach, hrob 31 - Pič 1902-1903, 484, tab. LIII: 15). Na území lužickej kultúry v Pol’sku sa vyskytujú o niečo častejšie ako na Morave, avšak i tam sú zastúpené pomerne zriedkavo (pozri Gedl 1991, 82-84; Ibragimow 2011). Ich výskyt v hroboch súvisí podla M. Gedla (1991, 82) so zosilnením vplyvov halštatskej kultúry. Práve pre halštatskú kultúru, a to tak východo-, ako aj západohalštatskú kultúrnu oblast', sú železné pásové zápony rombického tvaru charakteristickou súčastou odevu (obr. 2). Vo vel'kom počte sa objavujú v Slovinsku v povodí rieky Sáva a v Dolenjsku (Gabrovec a i. 2006, 38-71, tab. 25: 30-2; 53: 89-2; Tecco Hvala 2012, 165-169, obr. 63: 5-19), čo viedlo k názoru, že ide o produkt juhovýchodohalštatskej kultúrnej oblasti (Kossack 1959a, 32-112; 1959b, tab. 154C; Torbrügge 1979, 89). Výrazne sú však zastúpené aj v západohalštatskej oblasti (Stöllner 2002, 91, obr. 36). Početne sa vyskytujú najmä v Hornom Bavorsku a Hornom Falcku (Torbrügge 1965, 62-317; 1979, 301-353), ale vo väčšom počte sa objavujú aj na pohrebisku v Hallstatte, kde sú zastúpené tak exempláre vyrobené zo železa (Kromer 1959b, tab. 5: 8; 12: 4; 32: 5; 69: 9), ako aj z bronzu (Kromer 1959b, tab. 1: 14; 8: 1). Práve v bavorsko-salzburskej oblasti rombické pásové zápony predstavujú dominantný tvar (Stöllner 2002, 91). Naopak, len ojedinele sa vyskytujú v Baden-Württembergsku (napr. Gammertingen-Kattenacker - Zürn 1987, 175, tab. 344: C2) a v oblasti Stredohoria (Mittelgebirgsraum) sa nevyskytujú vôbec (Nikulka 1998, 60). V malom počte sa objavujú v Čechách (napr. pohrebisko pri Mírkoviciach, mohyly IX a XI - Chytráček 1990, 92-97, obr. 16: 5; 18: 10, 11) a v Dolnom Rakúsku (napr. Bischofshofen-Pestfriedhof - Lippert/Stadler 2009a, 43; 2009b, tab. 55: 214/3; 166: 556/12; Maiersch - Berg 1962, 13-29, tab. 18: 5; Statzendorf - Rebay 2006a, 172; 2006b, tab. 149: PA43255; 195: PA56081). Z južnej Moravy, prostredia susednej horákovskej kultúry, sú známe len fragmenty železných pásových zápon, u ktorých sa zachovali časti so záchytným koncom v tvare rybieho chvosta (Bošovice, mohyla 2, Těšetice, hrob 5 - Stegmann-Rajtár 1992, 46-60, tab. 93: 9; 126: 5).

Železné pásové zápony rombického tvaru z územia platěnickej kultúry na Morave možno datovat do stupňa HD. S týmto stupňom sú spájané aj v centre ich rozšírenia. V oblasti Inn-Salzach predstavujú rombické pásové zápony jeden z hlavných tvarov strednej doby halštatskej (stupeň HD1). Do tohto stupňa spadajú aj exempláre z územia južného Bavorska, avšak v Hornom Falcku sa ojedinele vyskytujú ešte v hroboch zo začiatku stupňa HD2 (Stöllner 2002, 91). S obomi stupňami ich možno spájat aj v Dolnom Bavorsku (Nikulka 1998, 60) a dlhší časový úsek používania, a to minimálne až do stupňa HD2, mali aj v d’alších susedných územiach ich rozšírenia. Počas stupňov HD1-HD3 (t. j. vo fáze hadovitých spôn, ako aj vo fáze certoských spôn) sa používali v Dolenjsku (Tecco Hvala 2012, 169).

\section{Bronzové plechové opasky}

Doposial' za jediný príklad bronzového plechového opasku, príp. plechovej obdížnikovitej pásovej zápony možno považovat niekol'ko zlomkov bronzového plechu s vybíjanou výzdobou, ktoré sa našli v hrobe 1119 na pohrebisku v Moravičanoch (obr. 3: 1). Korózia na železných nitoch naznačuje stret s organickým materiálom. Je preto vel'mi pravdepodobné, že bronzový plech bol pripevnený na kožu alebo textíliu (pozri Grömer 2010, 287, obr. 143). Súčastou opasku bol zrejme aj zlomok železného krúžku (obr. 
3: 2) a zlomok železného tyčinkového predmetu so slučkovitým ukončením, ku ktorému je koróziou pripevnený zlomok nejakého d’alšieho predmetu (obr. 3: 3). Pravdepodobne ide o predmet, ktorý bol k opasku pripevnený a slúžil na zavesenie nejakých d’alších predmetov. Podobná železná tyčinka sa našla spolu so zlomkami iných tyčiniek a fragmentom železnej pásovej zápony v mohyle 9 na pohrebisku Riedenburg-Emmerthal v Dolnom Bavorsku, pričom je velmi pravdepodobné, že všetky menované predmety tvorili súčast' jedného opaska (Schanz 1997, 60, tab. 34).

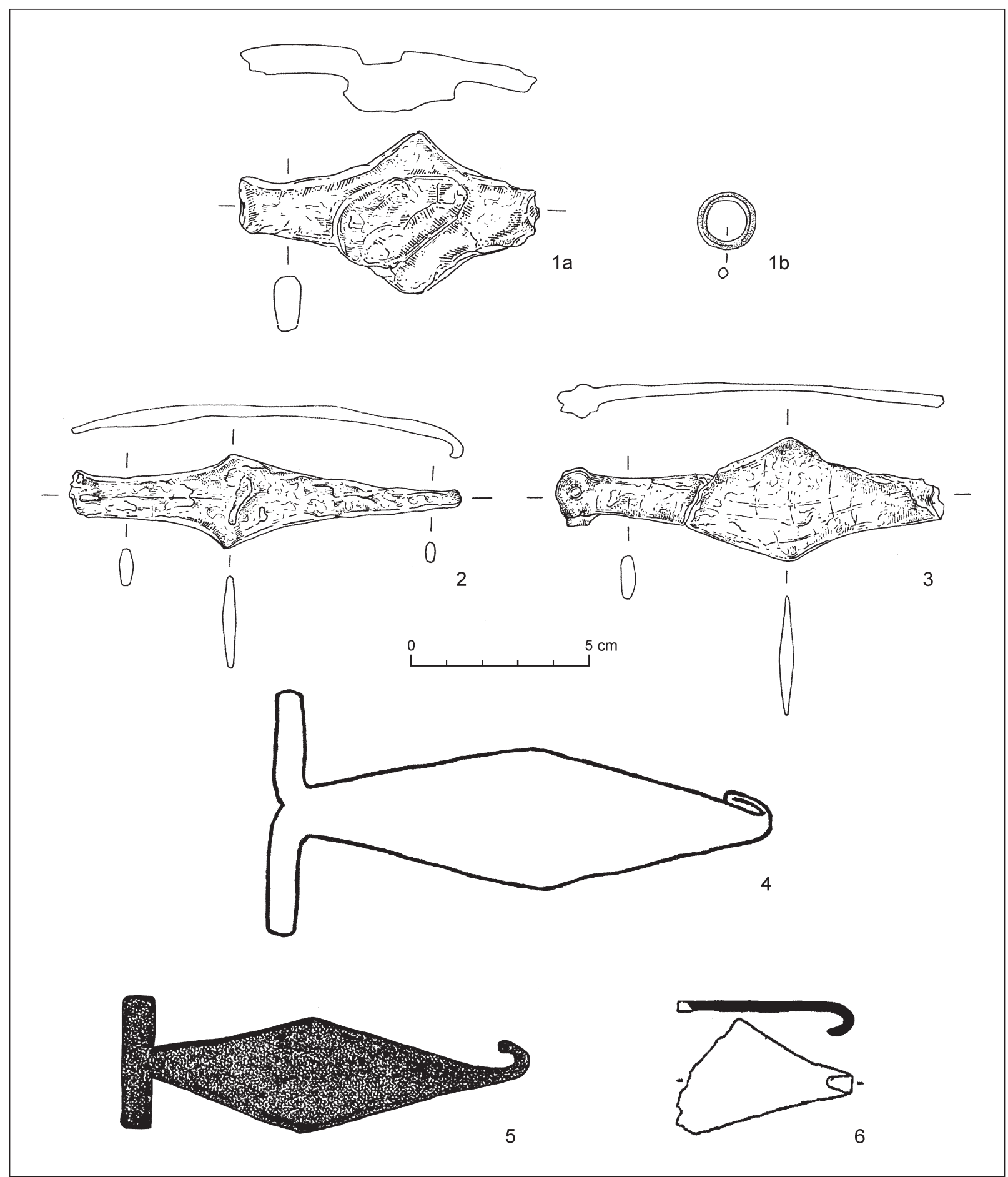

Obr. 1. Železné pásové zápony rombického tvaru. 1 - Moravičany, hrob 1000; 2 - Moravičany, hrob 1144; 3 - Moravičany, hrob 1145; 4 - Dobrčice; 5 - Uherský Ostroh-Ostrožské Předměstí; 6 - Mohelnice, hrob 4. 1b - bronz; ostatné železo (1-3 - kresba Š. Trávničková; 4 - podl’a Červinka 1938, obr. 1: 3; 5 - podl’a Myklík 1887, obr. 6: 16; 6 - podl’a Stuchlík 2004, obr. 3: 4). 


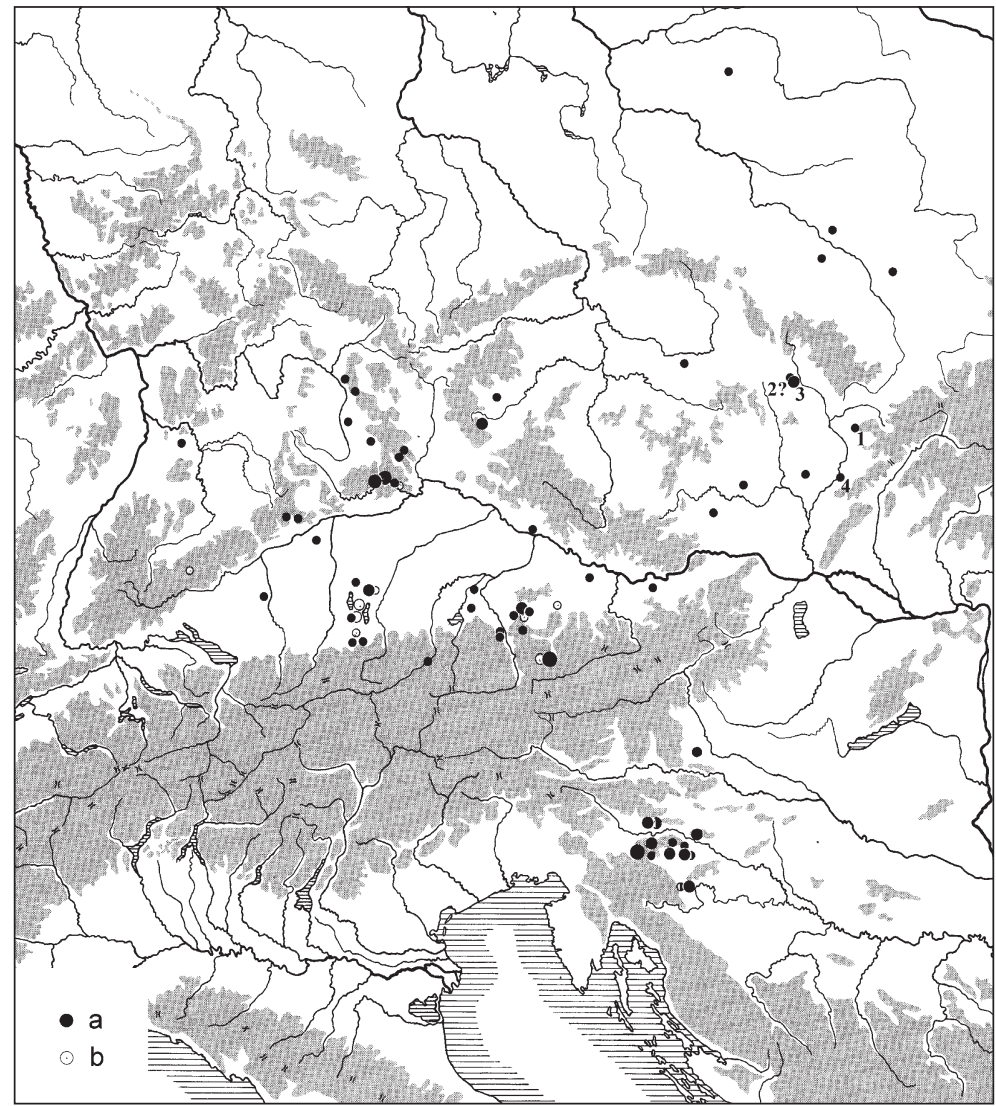

Obr. 2. Rozšírenie železných pásových zápon rombického tvaru. Rozšírenie v prostredí platěnickej kultúry: 1 - Dobrčice; 2 - Mohelnice; 3 - Moravičany; 4 - Uherský Ostroh-Ostrožské Předměstí (podla Stöllner 2002, obr. 36, s úpravami). a - zápony s koncom tvaru rybieho chvosta; $\mathrm{b}$ - zápony s odsadenou platničkou na nity. nálezov šperkov a súčastí odevu datovaný do stupňa HD1 (Kilian-Dirlmeier 1972, 107, tab. 49: 653-655; Kromer 1959b, tab. 243: 1). Bronzové plechové opasky sú charakteristické skôr pre východnú oblast' rozšírenia západohalštatskej kultúry a radia sa k uprednostňovaným tvarom v oblasti Inn-Salzach (Rebay 2006a, 171, 172; Stöllner 2002, 94). Naproti tomu obdĺžnikovité bronzové plechové pásové zápony boli populárne aj v Dolenjsku. Vo vysokom počte sa objavili v Magdalenskej gore, kde sa vyskytli dva varianty, a to zápony, ktoré boli podložené železným plátom, pásmi či so železným háčikom, a zápony bez železného podloženia (Tecco Hvala 2012, 170-180, obr. 65, 66).

\section{OPASOK AKO SÚČASŤ KROJA}

O vzhl'ade mužského a ženského kroja z doby halštatskej máme informácie z viacerých zdrojov (pozri Grömer 2010, 353-372). Vyobrazenia na situlovom umení znázorňujú ženy, ktoré mali šaty s opaskom uviazaným okolo pása (Lucke/Frey 1962, tab. 5; 38; 64; 76) a s opaskom sú zobrazení aj muži - zápasníci, bojovníci a pol’ovníci, z ktorých niektorí majú k pásu pripevnenú zbraň (Lucke/Frey 1962, tab. 42; 61; 63; 65; 69; 72; 73; 76). Zdobený opasok je tu znázornený pomerne často, pričom pravdepodobne nejde len o znázornenie opaska zhotoveného z textilu a kože, ale aj o vyobrazenia kovového plechového opaska (Kurzynski 1996, 48). Za znázornenie textilných opaskov zrejme môžeme považovat tie vyobrazenia, kde má opasok rovnakú výzdobu ako lem šiat (napr. situla z Magdalenenbergu; Lucke/Frey 1962, tab. 68), zatial čo kovové opasky zrejme predstavujú vyobrazenia širších pásov, ktorých výzdoba sa s tou, ktorá šaty lemuje, nezhoduje (napr. situla v Providance; Lucke/Frey 1962, tab. 5). 

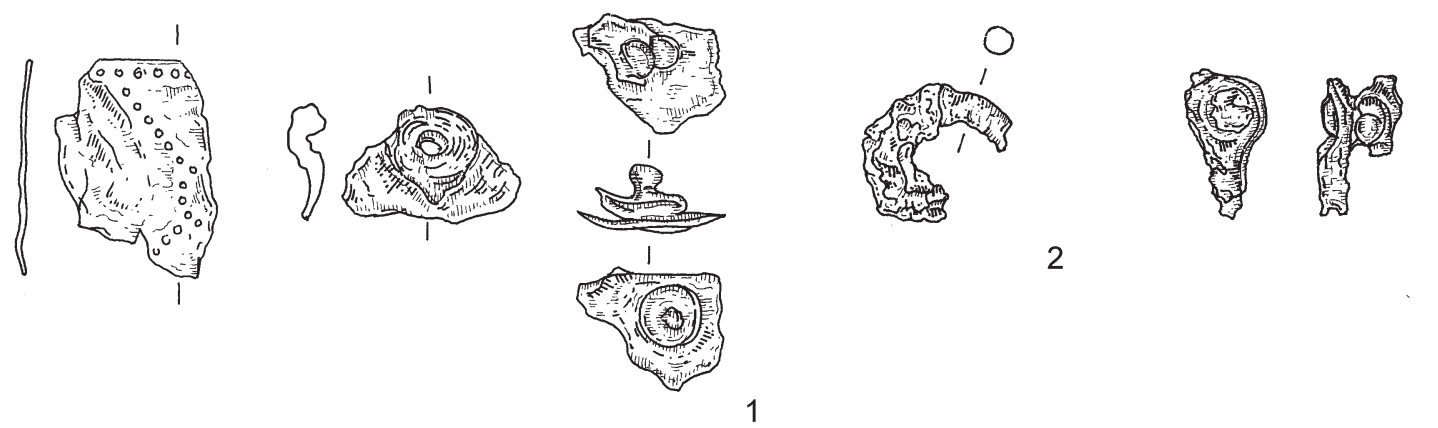

2
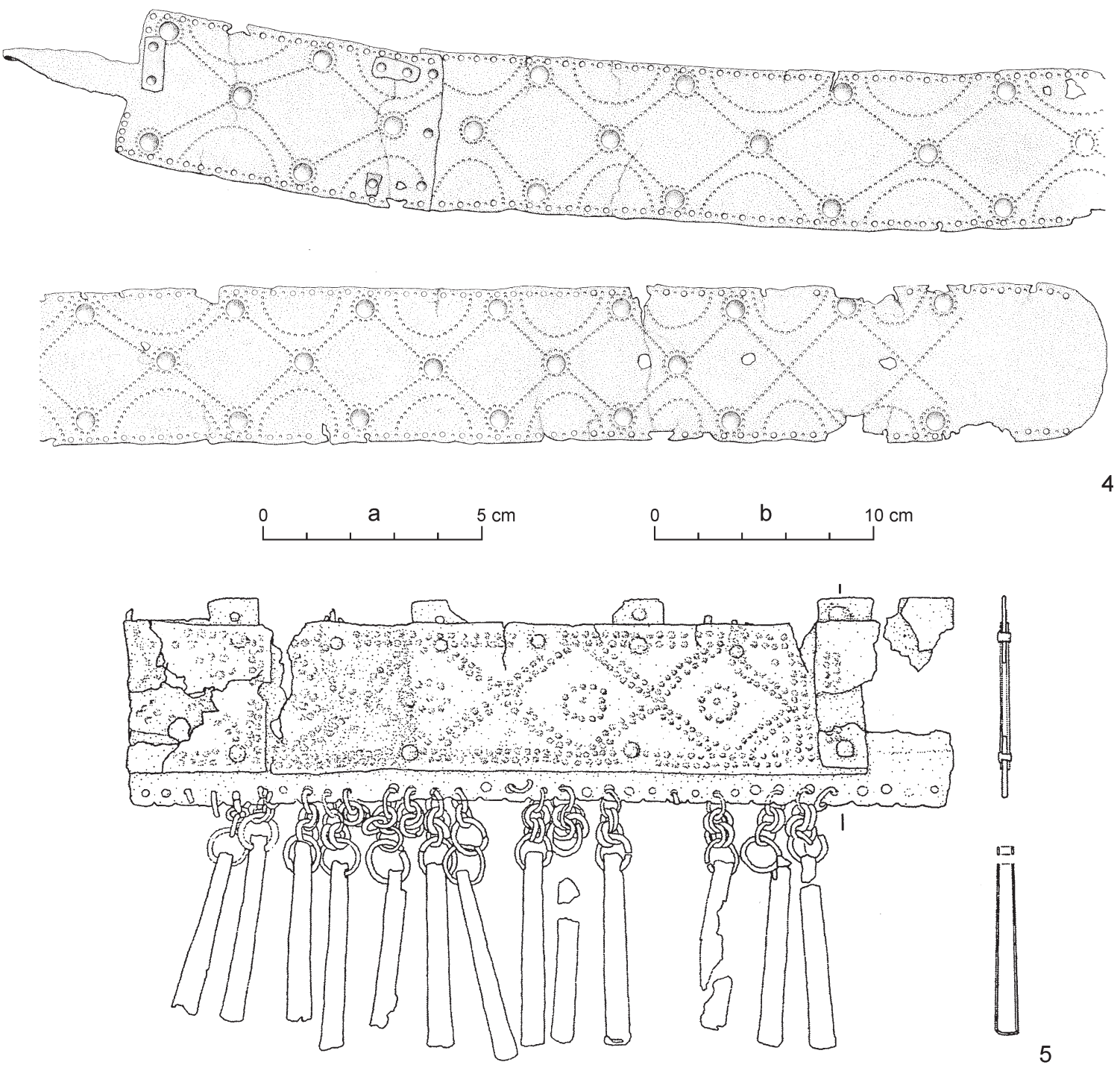

Obr. 3. Bronzový plechový opasok. 1-3 - Moravičany, hrob 1119; 4 - Amstetten; 5 - Montegiorgio, hrob 39. 1, 4, 5 - bronz; 2, 3 - železo. Mierka: a - 1-3; b - 4; bez mierky - 5 (1-3 - kresba Š. Trávničková; 4 - podla Kilian-Dirlmeier 1972, tab. 76, 77: 634; 5 - podla Seidel 2006, tab. 49: 1). 
Príslušnost’ určitého typu opaska ku konkrétnemu pohlaviu je často diskutabilná, kedže v mnohých prípadoch preferencia nosenia daného typu konkrétnym pohlavím súvisela s ich časovým, ako aj geografickým rozšírením. Príkladom toho je situácia v Hallstatte a Dürrnbergu, kde sa plechové kovania na opasok v stupni HD1 vyskytovali tak v hroboch mužov, ako aj žien, zatial' čo mladšie exempláre pochádzali z mužských hrobov. Hroby žien však boli od stupňa HD1 vybavené plechovými opaskami. S tým zrejme súvisí skutočnost', že bohato zdobené plechové kovania na opasok sa v oblasti Inn-Salzach nepresadili, ked’že ich miesto zaujali zdobené plechové opasky (Stöllner 2002, 94). Iná situácia je v Magdalenskej Gore, kde sa bronzové plechové obdlžnikovité pásové zápony nachádzali v kostrových hroboch so zbraňami. Zaujímavé je pritom zistenie, že zatial' čo bronzové plechové obdížnikovité pásové zápony podložené železným plátom alebo so železným háčikom boli súčastou kroja elít, tie exempláre, ktoré podložené neboli, len zriedka tvorili súčast’ takéhoto kroja (Tecco Hvala 2012, 173-175, obr. 67, 68). Ani výzdobu bronzových plechových opaskov a zápon nie je možné vždy spájat s konkrétnym pohlavím. Podla I. Kilianovej-Dirlmeierovej $(1972,124-129)$ sa však zdá, že vybíjaná výzdoba sa objavovala skôr na opaskoch nosených ženami.

Rovnako aj v prípade železných pásových zápon, ktoré sa vo všeobecnosti považujú za súčast̉ odevu mužov, zohrávala geografická poloha lokalít istú rolu pri ich nosení konkrétnym pohlavím. Zatial' čo v oblasti Inn-Salzach sa rombické pásové zápony objavujú tak v hroboch mužov, ako aj žien (Lippert/Stadler 2009a, 43; Stöllner 2002, 91), v Bavorsku sú spájané s pohrebmi mužov (Torbrügge 1979, 94), i ked' napríklad na pohrebisku v Riedenburg-Untereggersbergu v Dolnom Bavorsku sa objavili nielen v mužských, ale aj v ženských hroboch (Nikulka 1998, 60). S mužským pohlavím sú spájané i nálezy pásových zápon z pohrebiska v Hallstatte, kde boli súčastou vybavenia mladších bojovníckych hrobov (Kromer 1959a, 27). Rovnako vo juhovýchodhalštatskej oblasti, v Dolenjsku, patrili pásové zápony $\mathrm{k}$ bežnej súčasti mužského kroja. Objavujú sa prevažne v hroboch so zbraňami, prípadne bez charakteristickej výbavy, zatial' čo v hroboch obsahujúcich šperky sa nachádzajú len zriedka (Stöllner 2002, 91, 92; Tecco Hvala 2012, 165-167, obr. 64). V prostredí horákovskej kultúry nie sú železné pásové zápony rombického tvaru bezpečne doložené, avšak zlomky železných zápon sa našli v hroboch (Bošovice, mohyla 2 - StegmannRajtár 1992, 46, tab. 93; Šolle 1955, 123, obr. 12: 7-10; Těšetice, hrob 5 - Podborský 1960, 644; Stegmann-Rajtár 1992, tab. 126), ktoré na základe výbavy (železná kopija, súčasti konského postroja a kamenný brúsik) môžu byt považované za hroby mužov. Železná pásová zápona oválneho tvaru však pochádza z hrobu (Mohelno - Stegmann-Rajtár 1992, tab. 88: 4), ktorý na základe hrobového inventára (železné náramky, sklený korálik a hrkálka) môže byt považovaný skôr za hrob ženy.

Pohlavie pochovaných jedincov z moravičanských hrobov, z ktorých pochádzajú vyššie analyzované časti opaskov, sa antropologickou analýzou nedalo určit. $V$ troch prípadoch bol však určený vek pochovaných jedincov. Išlo o dospelých jedincov, pričom $\mathrm{v}$ dvoch prípadoch bol určený aj bližší vek $-\mathrm{v}$ jednom hrobe bol pochovaný jedinec vo veku adultus, v druhom vo veku maturus (Stloukal, b. r. v.). Hrobový inventár komorových hrobov (hroty šípov, pinzeta a britva), v ktorých sa našli pásové zápony indikuje, že išlo pravdepodobne o hroby mužov (Makarová 2017a, 117, 118). Za hrob muža možno považovat' aj hrob so železnou rombickou pásovou záponou z Dobrčíc (Makarová 2013, 102, 103), čo by mohlo naznačovat', že rovnako ako v prípade Bavorska či Dolenjska, takýto typ opaska tvoril súčast mužského kroja. Komplikovanejšia situácia je v prípade fragmentov bronzového plechu. Na základe hrobovej výbavy sa nedá určit, či bol v hrobe pochovaný muž alebo žena, hoci by sme sa azda mohli skôr prikláňat k osobe ženského pohlavia (Makarová 2017a, 114, 118). Fragmentárnost̉ nálezu nedovoluje určit, či išlo o plechový opasok alebo o plechovú pásovú záponu, preto ani nálezové situácie z iných oblastí, kde sa zdá, že opasok s plechovým kovaním, resp. obdĺžnikovitou plechovou pásovou záponou tvoril súčast̉ mužského a plechový opasok zas súčast’ ženského kroja, neprinášajú svetlo do tejto problematiky.

Nálezové situácie z pohrebiska v Moravičanoch poukazujú na to, že opasok s kovovými častami patril ku kroju osôb s vyšším sociálnym statusom. Všetky tri železné pásové zápony sa našli v komorových hroboch, zlomky bronzového opasku/pásovej zápony zas v hrobe s vyšším počtom kovových predmetov. Na výnimočnost’ osôb poukazuje tiež samotný fakt, že táto súčast’ kroja sa objavuje v prostredí platěnickej kultúry len výnimočne a v neposlednom rade i to, že sú dokladom kontaktov platěnickej kultúry s centrami halštatskej kultúry. 


\section{ZÁVER}

Fragmenty bronzového plechového opasku, príp. obdížnikovitej plechovej pásovej zápony a železné pásové zápony rombického tvaru, ktoré sa našli na pohrebisku v Moravičanoch, predstavujú významný dôkaz o kontaktoch medzi platěnickou a halštatskou kultúrou. Oba typy opaskov jasne poukazujú na zmeny v kroji, ktoré korešpondujú so zmenami v pohrebnom ríte platěnickej kultúry spôsobené vplyvmi halštatskej kultúry. Otázka, či sa tieto predmety (či už priamo ako importy, alebo nepriamo ako miestne napodobeniny) dostali do prostredia platěnickej kultúry zo západohalštatskej alebo juhovýchodohalštatskej kultúrnej oblasti, zostáva zatial' nezodpovedaná. O kontaktoch platěnickej kultúry s obidvomi oblastami svedčia totiž viaceré nálezy objavené priamo na pohrebisku v Moravičanoch, ako aj nálezy z iných lokalít (Makarová 2017a; 2017b). Rovnako nie je bezpečne doložené, či boli tieto opasky nosené mužmi alebo ženami, ale zdá sa, že železné pásové zápony rombického tvaru boli súčastou kroja mužskej „elity“ v stupni HD.

\section{LITERATÚRA}

Berg 1962

Červinka 1938

Fath/Glunz-Hüsken 2011

Gabrovec a i. 2006

Gedl 1991

Grömer 2010

Heynowski 2017

Chytráček 1990

Ibragimow 2011

Kilian-Dirlmeier 1972

Kos 2004

Kossack $1959 a$

Kossack 1959b

Kromer 1959 a

Kromer $1959 b$

Kurzynski 1996

Lenneis 1972

Lippert/Stadler 2009a

Lippert/Stadler 2009 b

Lucke/Frey 1962
F. Berg: Das Flachgräberfeld der Hallstattkultur von Maiersch. Veröffentlichungen der Österreichischen Arbeitsgemeinschaft für Ur- und Frühgeschichte IV. Wien 1962. I. L. Červinka: Nálezy z Přerovska. Ročenka Městského musea v Přerově 2, 1938, 78 86.

B. Fath/B. Glunz-Hüsken: Textilien und Symbole für ihre Herstellung in eisenzeitlichen Gräbern Mitteleuropas Griechenland - Este - Frög - Sopron. Prähistorische Zeitschrift 86/2, 2011, 254-271.

S. Gabrovec/A. Kruh/I. Murgelj/B. Teržan: Stična II/1. Gomile starejše železne dobe. Grabhügel aus der älteren Eisenzeit. Katalog. Katalogi in monografije 37. Ljubljana 2006.

M. Gedl: Die Hallstatteinflüsse auf den polnischen Gebieten in der Früheisenzeit. Zeszyty Naukowe Uniwersytetu Jagiellońskiego 969. Prace archeologiczne 48. Warszawa Kraków 1991.

K. Grömer: Prähistorische Textilkunst in Mitteleuropa. Geschichte des Handwerkes und Kleidung vor den Römern. Wien 2010.

R. Heynowski: Gürtel. Erkennen - Bestimmen - Beschreiben. München 2017.

M. Chytráček: Mohylové pohřebiště u Mírkovic, okres Domažlice. Památky archeologické 81, 1990, 74-139.

K. Ibragimow: Halsztacka klamra do pasa z cmentarzyska kultury łużyckiej w Niezgodzie, stanowisko 1, pow. Trzebnicki. Ślaskie sprawozdania archeologiczne 53, 2011, 5-17.

I. Kilian-Dirlmeier: Die hallstattzeitlichen Gürtelbleche und Blechgürtel Mitteleuropas. Prähistorisches Bronzefunde XII/1. München 1972.

P. Kos: Pohřby žen z doby halštatské v Modřicích u Brna. In: Popelnicová pole a doba halštatská. Př́spěvky z VIII. konference, České Budějovice 22.-24. 9. 2004. Archeologické výzkumy v jižních Čechách. Supplementum 1. České Budějovice 2004, 271-292. G. Kossack: Südbayern während der Hallstattzeit. Text. Berlin 1959.

G. Kossack: Südbayern während der Hallstattzeit. Tafeln. Berlin 1959.

K. Kromer: Das Gräberfeld von Hallstatt. Textband. Firenze 1959.

K. Kromer: Das Gräberfeld von Hallstatt. Tafelband. Firenze 1959.

K. v. Kurzynski: „....und ihre Hosen nennen sie bracas“. Textilfunde und Textiltechnologie der Hallstatt- und Latènezeit und ihr Kontext. Internationale Archäologie 22. Espelkamp 1996.

E. Lenneis: Die Frauentracht des Situlenstiles - ein Rekonstruktionsversuch. Archaeologia Austriaca 51, 1972, 16-57.

A. Lippert/P. Stadler: Das spätbronze- und früheisenzeiltliche Gräberfeld von Bischofshofen-Pestfriedhof. Teil 1. Bearbeitung und Auswertung. Universitätsforschungen zur prähistorischen Archäologie 168. Bonn 2009.

A. Lippert/P. Stadler: Das spätbronze- und früheisenzeiltliche Gräberfeld von Bischofshofen-Pestfriedhof. Teil 2. Katalog und Tafeln. Universitätsforschungen zur prähistorischen Archäologie 168. Bonn 2009.

W. Lucke/O.-H. Frey: Die Situla in Providence (Rhode Island). Ein Beitrag zur Situlenkunst des Osthallstattkreises. Römisch-Germanische Forschungen 26. Berlin 1962. 
Makarová 2013

Makarová 2017a

Makarová $2017 b$

Myklík 1887

Nekvasil 1982

Nikulka 1998

Pare 1987

Píč 1902-1903

Podborský 1960

Rebay $2006 a$

Rebay $2006 b$

Seidel 2006

Schanz 1997

Stegmann-Rajtár 1992

Stloukal, b.r. v.

Stöllner 2002

Stuchlík 2004

Šlle 1955

Tecco Hvala 2012

Torbrügge 1965

Torbrügge 1979

Zürn 1987
E. Makarová: Chamber tombs of the Platěnice culture - elite burials? In: R. Karl/J. Leskovar (Hrsg.): Interpretierte Eisenzeiten: Fallstudien, Methoden, Theorie. Tagungsbeiträge der 5. Linzer Gespräche zur interpretativen Eisenzeitarchäologie. Studien zur Kulturgeschichte von Oberösterreich 37. Linz 2013, 95-106.

E. Makarová: Halštatská fáza pohrebiska v Moravičanoch. Dizertačná práca (Masarykova univerzita). Brno 2017. Nepublikované.

E. Makarová: Moravia - A Connecting Line between North, West and South. To the Supra-regional Connections and Formation of Elites in the Early Hallstatt Period. In: R. Schumann/S. van der Vaart-Verschoof (eds.): Connected Elites and Regions. Perspectives on contacts, relations and differentiation during the Early Iron Age Hallstatt C period in Northwest and Central Europe. Leiden 2017, 29-48.

F. Myklík: Ze Bzence (Nález na Předměstí Uh. Ostrožském a jiné nálezy v okolí Bzeneckém). Časopis Vlasteneckého spolku muzejního v Olomouci 14, 1887, 81-88.

J. Nekvasil: Pohřebiště lužické kultury v Moravičanech. Katalog nálezủ. Brno 1982.

F. Nikulka: Das hallstatt- und frühlatènezeitliche Gräberfeld von Riedenburg-Untereggersberg, Lkr. Kelheim, Niederbayern. Archäologie am Main-Donau-Kanal 13. Rahden/Westf. 1998.

Ch. Pare: Der Zeremonialwagen der Hallstattzeit: Untersuchungen zu Konstruktion, Typologie und Kulturbeziehungen. In: Vierrädrige Wagen der Hallstattzeit: Untersuchungen zu Geschichte und Technik. Monographien Römisch-Germanisches Zentralmuseum 12. Mainz 1987, 189-248.

J. L. Píć: Nový typ žárových hrobů v Čechách. Památky archeologické 20, 1902-1903, 467-508, tab. XLVII-LXVII.

V. Podborský: Halštatské pohřebiště v Těšeticích na Moravě. Archeologické rozhledy 12, 643-650.

K. C. Rebay: Das hallstattzeitliche Gräberfeld von Statzendorf in Niederösterreich. Möglichkeiten und Grenzen der Interpretation von Sozialindexberechnungen. Teil 1. Universitätsforschungen zur prähistorischen Archäologie 135. Bonn 2006.

K. C. Rebay: Das hallstattzeitliche Gräberfeld von Statzendorf in Niederösterreich. Möglichkeiten und Grenzen der Interpretation von Sozialindexberechnungen. Teil 2. Katalog. Universitätsforschungen zur prähistorischen Archäologie 135. Bonn 2006.

S. Seidel: Die „Grabkomplexe“ aus Montegiorgio - Untersuchungen zur Tracht und kulturhistorischen, regionalen Einordnung. In: P. Ettel/A. Naso (Hrsg.): Montegiorgio. Die Sammlung Compagnoni Natali in Jena. Jenaer Schriften zur Vor- und Frühgeschichte 2. Jena 2006, 74-166.

E. Schanz: Das bronze- und hallstattzeitliche Gräberfeld von Riedenburg-Emmerthal, Lkr. Kelheim, Niederbayern. Archäologie am Main-Donau-Kanal 11. Espelkamp 1997.

S. Stegmann-Rajtár: Grabfunde der älteren Hallstattzeit aus Südmähren. Košice 1992.

M. Stolukal: Základní určení žárových pohřbů z Moravičan. Strojopisné poznámky. Archeologický ústav AV ČR. Brno, b. r. v.

T. Stöllner: Die Hallstattzeit und der Beginn der Latènezeit im Inn-Salzach-Raum. Auswertung. Archäologie in Salzburg 3/I. Salzburg 2002.

S. Stuchlík: Halštatské pohřebiště v Mohelnici u Zábřeha. In: Popelnicová pole a doba halštatská. Př́spěvky z VIII. konference, České Budějovice 22.-24. 9. 2004. Archeologické výzkumy v jižních Čechách, Supplementum 1. České Budějovice 2004, 523-533. M. Šolle: Jižní Morava v době halštatské. Památky archeologické 46, 1955, 101-133.

S. Tecco Hvala: Magdalenska gora. Družbena struktura in grobni rituali železnodobne skupnosti = Magdalenska gora. Social structure and biritual rites of the Iron Age community. Opera Instituti Archaeologici Sloveniae 26. Ljubljana 2012.

W. Torbrügge: Hallstattzeit in der Oberpfalz II. Die Funde und Fundplätze in der Gemeinde Beilngries. Materialhefte zur bayerischen Vorgeschichte 20. Kallmünz/Opf. 1965. W. Torbrügge: Hallstattzeit in der Oberpfalz I. Auswertung und Gesamtkatalog. Materialhefte zur bayerischen Vorgeschichte 39. Kallmünz/Opf. 1979.

H. Zürn: Hallstattzeitliche Grabfunde in Württemberg und Hohenzollern. Stuttgart 1987. 


\title{
Belt from the cemetery in Moravičany as an evidence of the supra-regional contacts of the Platěnice culture
}

\author{
Erika Makarová
}

Summary

Metal parts of belts occur quite sporadically in the Platěnice culture in Moravia. These are mostly closed iron (Fig. 3: 2) and bronze rings (Fig. 1: 1b) that might be considered the belt rings, iron belt hooks occur less often. These components of belt were found also at the cemetery in Moravičany, site Dílečky, the largest cemetery of the Platěnice culture excavated in 1953-1955 and 1958-1968 by J. Nekvasil.

Apart from three iron rhombic belt hooks from chamber graves nr. 1000 (Fig. 1: 1a), 1144 (Fig. 1: 2) and 1145 (Fig. 1: 3), fragments of decorated bronze sheet belonging to sheet-bronze belt or rectangular sheet-bronze belt hook were found in grave nr. 1119 (Fig. 3: 1).

There are only five iron rhombic belt hooks known with certainty from the Platěnice culture by now. They are typical for the western Hallstatt culture, mainly Bavaria-Salzburg region, as well as the south-eastern Hallstatt culture, in Slovenia in the Sava river basin and Lower Carniola (Dolenjska; Fig. 2). Usually, they were part of the male costume, but in some regions they occur also in female graves. According to the finds from the cemeteries of Moravičany and Dobrčice, it seems that the iron rhombic belt hooks were worn by higher-social-rank men (chamber graves, weapons and horse harness) in the Platěnice culture in the Ha D phase as well.

More complicated situation is in the case of sheet-bronze fragments from grave 1119. Although it is sure that they represent the parts of one belt, it is unknown whether it was the sheet-bronze belt or rectangular sheet-bronze belt hook. While the sheet-bronze belts were typical rather for the east part of the western Hallstatt culture, the rectangular sheetbronze belt hooks occurred in western, eastern as well as south-eastern Hallstatt culture. As for its decoration, the best parallel to the ornament on the fragments of bronze sheet from Moravičany is on the sheet-bronze belt from the grave in Amstetten, Lower Austria. Gender of deceased from Moravičany grave 1119 was not determined by anthropologist and artefactual determination of gender as female cannot be sufficiently proved.

Ultimately, the four parts of four belts from Moravičany present an important evidence on contacts between Hallstatt and Platěnice cultures. The belts clearly represent a change in costume, which well corroborates to already known changes in the burial rite of Platěnice culture induced by the Hallstatt milieu.

Fig. 1. Iron rhombic belt hooks. 1 - Moravičany, grave 1000; 2 - Moravičany, grave 1144; 3 - Moravičany, grave 1145; 4 Dobrčice; 5 - Uherský Ostroh-Ostrožské Předměstí; 6 - Mohelnice, grave 4 . 1b - bronze; others iron (1-3 - drawing Š. Trávničková; 4 - after Červinka 1938, fig. 1: 3; 5 - after Myklík 1887, fig. 6: 16; 6 - after Stuchlík 2004, fig. 3: 4).

Fig. 2. Distribution of iron belt rhombic belt hooks. Distribution in the Platěnice culture: 1 - Dobrčice; 2 - Mohelnice; 3 - Moravičany; 4 - Uherský Ostroh-Ostrožské Předměstí (after Stöllner 2002, fig. 36, with additions). a - belt hooks with a swallowtail terminal; $b$ - belt hooks with a separate rivate plate.

Fig. 3. Sheet bronze belt. 1-3 - Moravičany, grave 1119; 4 - Amstetten; 5 - Montegiorgio, grave 39. 1, 4, 5: bronze; 2, 3 iron. Scale: a - 1-3; b - 4; without scale - 5 (1-3 - drawing Š. Trávničková; 4 - after Kilian-Dirlmeier 1972, Tab. 76, 77: 634; 5 - after Seidel 2006, tab. 49: 1).

Mgr. Erika Makarová, PhD.

Filozofická fakulta Univerzity Komenského

Katedra archeológie

Gondova 2

SK - 81499 Bratislava

erika.makarova@gmail.com 